\title{
Mitochondrial DNA D-loop haplogroup contributions to the genetic diversity of East European domestic chickens from Russia
}

\author{
A.G. Dyomin ${ }^{1}$, M.I. Danilova ${ }^{1}$, J.M. Mwacharo ${ }^{2, *}$, A.E. Masharsky ${ }^{3}$, A.V. Panteleev ${ }^{4}$, A.S. Druzhkova ${ }^{5}$, \\ V.A. Trifonov ${ }^{5}$ \& S.A. Galkina ${ }^{1}$ \\ 1 Faculty of Biology, Saint Petersburg State University, Saint Petersburg, Russia \\ 2 Centre for Genetics and Genomics, School of Life Sciences, University of Nottingham, Nottingham, UK \\ 3 Research Resource Centre for Molecular and Cell Technologies, Saint Petersburg State University, Saint Petersburg, Russia \\ 4 The Ornithology Department, Zoological Institute, Russian Academy of Science, Saint Petersburg, Russia \\ 5 Department of Genomic Diversity and Evolution, Institute of Molecular and Cellular Biology, Siberian Branch of the Russian Academy of Sciences, \\ Novosibirsk, Russia
}

\section{Keywords}

Ancient DNA; dispersal of chickens; diversity; Gallus gallus; gene pool; maternal lineage.

\section{Correspondence \\ S. Galkina, Oranienbaumskoe shosse, 2, Saint Petersburg 198504, Russia. \\ Tel: +78124507311; \\ Fax: +78124507310 \\ E-mail: svetlana.galkina@spbu.ru}

Received: 19 June 2016;

accepted: 7 November 2016

${ }^{*}$ Current address: International Centre for Agricultural Research in the Dry Areas, C/O ILRI-Addis Ababa, P.O. Box 5689 Addis Ababa, Ethiopia.

\section{Summary}

To elucidate geographical and historical aspects of chicken dispersal across Eastern Europe, we analysed the complete mitochondrial DNA D-loop sequence of 86 representatives from chicken breeds traditionally raised in the territory of the East European Plain (Orloff, Pavlov, Russian White, Yurlov Crower, Uzbek Game and Naked Neck). From the 1231-1232 bp D-loop sequence, 35 variable sites that defined 22 haplotypes were identified in modern chicken. All populations, except Uzbek Game, exhibited high values of haplotype and nucleotide diversity suggesting a wide variation in maternal diversity. Inclusion of mtDNA sequences from other European and Asian countries revealed representatives from this study belonging to haplogroups $\mathrm{A}, \mathrm{El}$ and $\mathrm{Cl}$. We also assessed fossil chicken material dated to the 9th-18th century from archaeological sites in Northern and Eastern Europe. Three haplotypes found in the fossil specimens belonged to haplogroup E1, while one sample dated to the 18th century was assigned to the $\mathrm{Cl}$ haplogroup. This is the first report of the occurrence of the $\mathrm{Cl}$ haplogroup in European chicken populations prior to the 20th century based on the fossil material. These results provide evidence for a relatively recent introduction of all haplotypes other than El into the East European chicken gene pool with the significant impact of the $\mathrm{Cl}$ haplogroup mainly distributed in Southern China.

\section{Introduction}

The analysis of mitochondrial DNA (mtDNA) sequence polymorphisms remains essential in understanding the domestication and demographic history of domestic animals. Analysis of the control (D-loop) region sequences or full mitochondrial genomes makes it possible to determine the number of maternal lines involved in the formation of breeds, assess their geographical origin and identify putative wild ancestral forms (Fumihito et al. 1994, 1996; Niu et al. 2002; Miao et al. 2013). Since the 2000s, the mtDNA has been used extensively to study genetic diversity and the origin of modern chicken populations, especially of South-East Asia, where the centres of initial domestication were most likely located (Niu et al. 2002; Liu et al. 2006; Miao et al. 2013). A classification of chicken mtDNA based on the variability of the Dloop region haplotypes was developed (Liu et al. 2006; Miao et al. 2013), and 11 major haplogroups A, B, C, 
D, E, F, G, H, I, X and W were identified (Miao et al. 2013). This classification system together with a massive amount of D-loop sequences from local populations and traditional breeds of chicken from different geographical regions that have been deposited in the GenBank are a valuable resource to study the maternal genetic diversity and origin of domestic chickens.

Chicken was domesticated nearly 8000 years ago in South and South-East Asia. During the next 5000 years, domestic chickens expanded through Western Asia to Northern Africa, Southern and Western Europe and by the 4th-2nd century before Christ (BC) they were kept by inhabitants of Greek, German, Belgium and English settlements (West \& Zhou 1989; Flink et al. 2014; Osman et al. 2016). The East European Plain with its famous communication waterways from the Varangians to the Greeks and to the Arabs thought to be important for chicken dispersal to Central and Northern Europe through Russia directly from Central Asia and China (West \& Zhou 1989; Crawford 1995). Archaeological findings indicate the presence of domestic chickens in Northern Europe (Novgorod region) by the 9th century BC (our data). The genetic diversity of East European chickens at the mtDNA level has been studied so far only in Hungarian (Revay et al. 2010) and Polish (Siwek et al. 2013) breeds. In our study, we aimed to analyse D-loop sequence variation of chicken breeds traditionally raised in the European part of Russia (Table 1) to fill a gap in describing of mtDNA polymorphisms in Eastern Europe.

The Orloff decorative chicken breed was created probably from mating of Gilan or Malay fighting chickens with unknown chickens having crests or with beards and muffs (Moiseeva 2006). The allele frequencies of serum and egg proteins clusters Orloff with Asiatic and sometimes European chickens (Moiseeva 2006). Pavlov is a medium-to-large-sized breed of chicken with a crest, muffs, beard and feathered feet. Data on biochemical polymorphisms show that Pavlov chickens are close to egg-type European breeds (Moiseyeva et al. 2003; Moiseeva 2006). The dualpurpose chicken breed Yurlov Crower originates presumably from the mating of Turkish Denizli chickens, some Chinese meat-type breeds, game breeds and local Russian chickens (Moiseeva 2006). Together with Orloffs and Pavlovs, Yurlov Crower chickens were included in the study of microsatellite polymorphisms within the framework of the international programme 'AVIANDIV' (Hillel et al. 2003). The medium-sized egg-layer Russian White chicken breed was created by mating indigenous Russian chickens and White Leghorn cocks. The analysis of serum esterase-
1 activity in various chicken breeds placed Russian White chickens to the 'Egg type with Mediterranean roots' group of breeds (Moiseyeva et al. 2003). The Naked Neck and Uzbek Game are regarded to be very old breeds in Russia, but their origins remain unknown. In chickens, the Naked Neck trait (locus $\mathrm{Na} / \mathrm{Na}$ ) is due to the presence of a large insertion located $260 \mathrm{~kb}$ upstream from the $3^{\prime}$-end of the gene BMP12 (Mou et al. 2011). It is speculated that the Naked Neck phenotype could have arrived in Central Europe via Russia (West \& Zhou 1989; Revay et al. 2010).

Dramatic changes in society during the years of the October revolution, civil and world wars affected negatively the state of traditional chicken breeds in Russia. In the 1960s, their restoration was initiated using a few remaining birds. In this study, we analysed complete D-loop sequence variation in Pavlov, Orloff, Yurlov Crower, Russian White, Naked Neck, Uzbek Game chicken breeds and of fossil samples from the territory of the East European (Russian) Plain to provide insights into the demographic history and dispersal pattern of mtDNA haplogroups across Eastern Europe.

\section{Materials and methods}

\section{Modern samples}

Eighty-six individuals representing six chicken breeds from Russia (Orloff (Spangled variety), Yurlov Crower, Russian White, Naked Neck, Uzbek Game and Pavlov) were selected for this study (Table 1). Genomic DNA was extracted from peripheral blood following standard procedures (Sambrook \& Russell 2001).

The complete mtDNA D-loop region (1231/ 1232 bp) from modern samples was amplified by PCR using the primers $1 \mathrm{~F}$ and $2 \mathrm{R}$ (Table S1) on an MJ Mini thermocycler (BioRad, Berkeley, CA, USA). All PCR reactions were carried out in $20 \mu \mathrm{l}$ reaction volumes containing $100 \mathrm{ng}$ of genomic DNA, $1 \times$ Taq-buffer, $2 \mathrm{~mm} \mathrm{MgCl}_{2}, 0.2 \mathrm{~mm}$ of each dNTP, $1 \mathrm{~mm}$ of each primer and 2.5 units of Taq DNA polymerase (Sileks, Moscow, Russia). The PCR protocol involved an initial denaturation at $94^{\circ} \mathrm{C}(4 \mathrm{~min}), 35$ cycles of denaturation at $94^{\circ} \mathrm{C}(30 \mathrm{~s})$, primer annealing at $60^{\circ} \mathrm{C}(35 \mathrm{~s})$ and elongation at $72^{\circ} \mathrm{C}(70 \mathrm{~s})$. A final extension step at $72^{\circ} \mathrm{C}(10 \mathrm{~min})$ completed the reactions. PCR products were sequenced using the BigDye ${ }^{\circledR}$ Terminator v3.1 Cycle Sequencing Kit (Applied Biosystems, Foster City, CA, USA) and 3500xL Genetic Analyzer (Applied Biosystems, Foster City, CA, USA). Together 
Table 1 List of chicken breeds and populations used in this study

\begin{tabular}{|c|c|c|c|c|c|c|}
\hline Breed & Abbreviation & $\begin{array}{l}\text { No. of } \\
\text { individuals }\end{array}$ & Source of samples & Origin & $\begin{array}{l}\text { Productivity } \\
\text { type }\end{array}$ & References \\
\hline Orloff & Orl & 12 & F.S.U.R.F. 'Gene Pool' ${ }^{1}$ & $\begin{array}{l}\text { Central Russia, late 18th } \\
\text { century }\end{array}$ & $\begin{array}{l}\text { Decorative - } \\
\text { Game }\end{array}$ & $\begin{array}{l}\text { Moiseyeva et al. 1994, 2003; } \\
\text { Hillel et al. 2003; Moiseeva } \\
\text { 2006; }\end{array}$ \\
\hline Pavlov & Pav & 37 & $\begin{array}{l}\text { F.S.U.R.F. 'Gene Pool' (10); } \\
\text { Moscow region²(18); } \\
\text { Barnaul }^{3}(9)\end{array}$ & $\begin{array}{l}\text { Middle Volga region, 18th } \\
\text { century }\end{array}$ & Decorative & $\begin{array}{l}\text { Moiseyeva et al. 2003; Hillel } \\
\text { et al. 2003; Moiseeva 2006; }\end{array}$ \\
\hline $\begin{array}{l}\text { Yurlov } \\
\text { Crower }\end{array}$ & Yu & 9 & F.S.U.R.F. 'Gene Pool' & $\begin{array}{l}\text { Central Russia (the Central } \\
\text { Black Earth Region), mid-19th } \\
\text { century }\end{array}$ & Meat - Egg & $\begin{array}{l}\text { Romanov \& Weigend 2001; } \\
\text { Hillel et al. 2003; Moiseeva } \\
\text { 2006; }\end{array}$ \\
\hline $\begin{array}{l}\text { Russian } \\
\text { White }\end{array}$ & RW & 7 & F.S.U.R.F. 'GenePool' & Industrial, 1929-1953 years & Egg & Moiseyeva et al. 2003; \\
\hline $\begin{array}{l}\text { Naked } \\
\text { Neck }\end{array}$ & NN & 9 & F.S.U.R.F. 'Gene Pool' & Unknown & Meat - Egg & \\
\hline $\begin{array}{l}\text { Uzbek } \\
\text { Game }\end{array}$ & Uz & 12 & F.S.U.R.F. 'Gene Pool' & Unknown & Game & Moiseeva 2006 \\
\hline
\end{tabular}

${ }^{1}$ Federal State Unitary research farm 'Gene Pool' (Genofond), Pushkin, Leningrad region, Russia.

${ }^{2}$ Fancy breeders, Moscow region, Russia.

${ }^{3}$ Fancy breeders, Barnaul, Altai region, Russia.

with the PCR primers, an additional pair of primers $3 \mathrm{~F}$ and $4 \mathrm{R}$ (Table S1) were used for sequencing. The obtained nucleotide sequences have been deposited at the GenBank (accession numbers KP307061KP307146, Table S2).

\section{Fossil specimens}

We extracted ancient DNA from chicken bones from five archaeological sites, Veliky Novgorod, Pskov, Saint Petersburg, Staraya Ladoga and Azov (Table S3), excavated under full authorization by Russian Federation government authorities. Bones were radiocarbon or stratigraphically dated to the 9th century AD (Veliky Novgorod), the 12th century AD (Staraya Ladoga), the 13-14th century AD (Azov) and to the 18th century AD (Pskov and Saint Petersburg) (Table S3).

DNA extractions, whole genome (WGA) and PCR amplifications were conducted in a specialized ancient DNA laboratory at the Department of Genomic Diversity and Evolution (Institute of Molecular and Cellular Biology, Siberian Branch of the Russian Academy of Sciences, Novosibirsk, Russia). All manipulations followed strict laboratory procedures to avoid contamination with modern DNA. DNA extraction and WGA procedures were performed as described by Druzhkova et al. (2013). We used three primer pairs $144 \mathrm{~F} /$ 387R, 218F/387R and 316F/586R (Table S1) for amplification of the hypervariable fragment (sites from 138 to $563 \mathrm{bp}$ of the D-loop region numbered according to NC007235). PCR was performed using
Phusion High-Fidelity DNA Polymerase (Thermo Scientific, Helsinki, Finland) following the manufacturer's instructions. For each PCR, we used standard concentrations of buffer (manufacturer-provided), dNTPs $(0.2 \mathrm{~mm})$, primers (1 $\mathrm{mm})$ and enzyme $(0.02$ $\mathrm{U} / \mu \mathrm{l}) .200 \mathrm{ng}$ of the WGA product was used as template to the $20 \mu \mathrm{l}$ PCR reaction mixture. We performed two rounds of PCR amplification according to the following protocol: an initial denaturation at $98^{\circ} \mathrm{C}$ ( $2 \mathrm{~min}$ ), 35 cycles of $10 \mathrm{~s}$ at $98^{\circ} \mathrm{C}, 25 \mathrm{~s}$ at $58^{\circ} \mathrm{C}$ and 20 $\mathrm{s}$ at $72^{\circ} \mathrm{C}$ and a final elongation step at $72^{\circ} \mathrm{C}(5 \mathrm{~min})$. Sequencing was performed using the three PCR primer pairs using the BigDye ${ }^{\circledR}$ Terminator v3.1 Cycle Sequencing Kit (Applied Biosystems, Foster City, CA, USA) and the 3500xL Genetic Analyzer (Applied Biosystems, Foster City, CA, USA). All procedures involving DNA extraction, WGA and PCR amplifications included negative controls that lacked bone powder or template DNA.

The primary analysis (viewing, manual editing and alignment) of individual nucleotide sequences and their subsequent categorization into distinct haplotypes was performed using BioEdit v.5.0.9. Nucleotide polymorphism $(\pi)$ and haplotype diversity (h) were calculated using DnaSP v.5.0.

\section{Phylogenetic analysis}

Molecular phylogenetic analyses were performed using the maximum parsimony (MP), maximum likelihood (ML) and Bayesian inference algorithms. Using 
Table 2 Sequence variations observed among 22 mtDNA D-loop haplotypes generated in a total of 86 samples from Orloff, Pavlov, Russian White, Yurlov Crower, Uzbek Game and Naked Neck breeds and five fossil mtDNA D-loop fragments. The reference sequence used here is the mtDNA fragment between 1 and 1232 bp of Gallus gallus spadiceus sequence NC007235 (Nishibori et al. 2005). An insertion/deletion (indel) mutation at position 859 bp was excluded from the analysis. Nucleotide positions that are identical to the reference sequence are indicated by dots. Abbreviations: Az - Azov (13-14th century), Psk - Pskov (18th century), SL - Staraya Ladoga (12th century), Nov - Veliky Novgorod (9th century), $\mathrm{SPb}$ - Saint Petersburg (18th century)

\begin{tabular}{|c|c|c|c|c|c|c|c|c|c|c|c|c|c|c|c|c|c|c|}
\hline Haplogroup & Haplotype & 73 & 97 & 140 & 167 & 199 & 210 & 212 & 217 & 221 & 222 & 225 & 239 & 242 & 243 & 246 & 250 & 256 \\
\hline Ref & NC007235 & A & c & A & T & $\mathrm{T}$ & C & A & $\mathrm{T}$ & c & A & c & A & G & $\mathrm{T}$ & T & c & T \\
\hline \multirow[t]{14}{*}{ E1 } & E1.1 & & . & . & . & . & & G & C & . & . & . & . & . & C & C & . & C \\
\hline & $\mathrm{E} 1.2$ & . & & & & & . & G & C & & & & & & C & C & & c \\
\hline & E1.3 & $C$ & G & & . & . & & G & C & . & . & . & & . & C & C & . & C \\
\hline & E1.4 & & G & . & . & . & & G & C & . & . & . & . & . & C & C & . & C \\
\hline & E1.5 & & . & . & . & c & & G & C & $\mathrm{T}$ & . & . & . & & c & c & . & c \\
\hline & E1.6 & . & & & & & . & G & C & . & G & & & & C & C & & C \\
\hline & E1.7 & . & & & & & . & G & C & & & & & & C & . & & C \\
\hline & E1.8 & & . & . & . & . & & G & C & - & . & . & . & . & C & C & . & C \\
\hline & E1.9 & & . & . & . & C & & G & C & . & . & . & . & . & C & C & . & C \\
\hline & E1.10 & & . & . & & . & & G & C & . & & . & . & & C & C & T & C \\
\hline & E1.11 & & . & . & . & . & & G & C & . & . & . & . & . & C & $C$ & . & C \\
\hline & E1.12 & & . & . & . & . & & G & C & 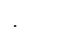 & . & . & . & . & C & C & . & C \\
\hline & E1.13 & & . & . & . & . & & G & C & . & . & . & . & . & C & C & . & C \\
\hline & E1.14 & . & & & & & . & G & C & & & & & & C & $C$ & & C \\
\hline $\mathrm{C} 1$ & C1.1 & & . & . & . & . & & G & & . & . & . & & A & C & C & . & C \\
\hline \multirow[t]{7}{*}{$A$} & $\mathrm{~A} 1$ & & . & . & C & . & T & G & & . & . & T & . & . & . & $C$ & . & \\
\hline & $\mathrm{A} 2$ & & . & . & C & . & & G & & . & & T & . & & . & $C$ & . & \\
\hline & A3 & . & & & C & & $T$ & G & . & . & & T & & & & C & & . \\
\hline & A4 & . & & & C & & . & G & . & & & T & & & & C & & . \\
\hline & A5 & & . & . & C & . & & G & & . & . & T & . & . & . & C & . & . \\
\hline & A6 & & . & . & c & . & & G & & & . & $\mathrm{T}$ & G & . & . & C & . & C \\
\hline & A7 & & . & . & C & . & T & G & & . & & . & . & & . & $C$ & . & C \\
\hline \multicolumn{19}{|c|}{ In Total: 35 variable sites } \\
\hline E1 & $\mathrm{Az}$ & & & & & & & & C & & . & . & . & . & C & C & . & C \\
\hline $\mathrm{C} 1$ & Psk & & & T & . & . & & G & . & & . & . & . & A & C & C & . & C \\
\hline E1 & SL & & & & & & & & C & & . & . & . & . & C & C & . & C \\
\hline E1 & Nov & & & $\mathrm{T}$ & . & . & & G & C & . & . & . & & . & C & $\mathrm{C}$ & . & C \\
\hline E1 & $\mathrm{SPb}$ & & & T & . & . & & G & $\mathrm{C}$ & & . & . & . & . & C & C & T & C \\
\hline \multicolumn{19}{|c|}{ In total with ancient DNA: 38 variable sites } \\
\hline
\end{tabular}

Mega 6.06, the HKY85+I+G (Hasegawa et al. 1985) and GTR $+G$ (Nei \& Kumar 2000) were determined to be the best-fit evolutionary models for the data set as deduced from the Akaike and Bayesian information criterions (AIC and BIC), respectively, and were used for the phylogenetic reconstructions. Mega 6.06 was used to perform the MP-tree searches and bootstrap estimation of node support. Bootstrap values were calculated with 500 replications. ML-phylogenetic tree was reconstructed with PhyML 3.0 using the HKY $85+\mathrm{I}+\mathrm{G}$ model. The reliability of the resulting tree topology was assessed using the approximate likelihood ratio test (aLRT) (Anisimova \& Gascuel 2006). The Bayesian inference method employing the GTR $+\mathrm{G}$ substitution model (Ronquist \& Huelsenbeck 2003) and executed in MrBayes 3.2.3 was used for phylogenetic tree reconstruction and posterior probability estimation.
For this analysis, we ran the Markov Chain MonteCarlo algorithm by simulating 10 million generations (the first $25 \%$ being discarded as burn-in) sampled every 1000 generations. The MP-tree was reconstructed using 86 full mtDNA D-loop sequences of modern Russian chickens and included 80 sequences downloaded from the GenBank to represent the 15 mtDNA haplogroups and subhaplogroups as reported by Miao et al. (2013) (Table S4). We included in the MP-tree analysis five DNA sequences of fossil specimens that we generated in this study.

To complement the phylogenetic analysis and obtain further insights into the genealogical relationships among haplotypes, we generated the median-joining (MJ) network using Network 4.613 software http://www.fluxus-engineering.com/share net.htm). We included in this analysis all the 86 


\begin{tabular}{|c|c|c|c|c|c|c|c|c|c|c|c|c|c|c|c|c|c|c|c|c|}
\hline 261 & 263 & 281 & 296 & 310 & 315 & 330 & 342 & 355 & 363 & 367 & 396 & 446 & 537 & 686 & 1139 & 1149 & 1157 & 1214 & 1215 & 1225 \\
\hline C & A & $A$ & C & C & $\mathrm{T}$ & C & $A$ & $T$ & C & $\mathrm{T}$ & $\mathrm{T}$ & C & $T$ & G & $A$ & A & C & C & $A$ & A \\
\hline $\mathrm{T}$ & & . & & $\mathrm{T}$ & C & & & & & & & $\mathrm{T}$ & . & & . & &. & T & G & \\
\hline $\mathrm{T}$ & . & . & . & $\mathrm{T}$ & C & . & . & . & . & . & . & $\mathrm{T}$ & . & . & $T$ & . & . & $\mathrm{T}$ & G & . \\
\hline $\mathrm{T}$ & . & . & . & $\mathrm{T}$ & C & . & . & . & . & . & . & $\mathrm{T}$ & & . & $\mathrm{T}$ & G & A & & G & . \\
\hline $\mathrm{T}$ & . & . & . & $\mathrm{T}$ & C & . & . & . & . & . & . & $\mathrm{T}$ & . & . & & . & . & $\mathrm{T}$ & G & . \\
\hline $\mathrm{T}$ & & . & & $\mathrm{T}$ & C & & & & & & . & $\mathrm{T}$ & . & . & . & . & . & $\mathrm{T}$ & G & \\
\hline $\mathrm{T}$ & . & & . & $T$ & C & $\mathrm{T}$ & & . & . & . & & $\mathrm{T}$ & & . & & . & & $T$ & G & \\
\hline $\mathrm{T}$ & . & & . & $\mathrm{T}$ & C & . & . & . & . & . & . & $\mathrm{T}$ & & . & & . & & $\mathrm{T}$ & G & . \\
\hline $\mathrm{T}$ & . & & . & $\mathrm{T}$ & C & . & . & C & . & . & & $\mathrm{T}$ & & . & & . & & $T$ & G & . \\
\hline $\mathrm{T}$ & . & . & & $\mathrm{T}$ & C & & . & . & & . & . & $\mathrm{T}$ & . & . & & . & . & $T$ & G & \\
\hline $\mathrm{T}$ & & . & & $\mathrm{T}$ & C & & & & & & & $\mathrm{T}$ & . & & . & & . & $\mathrm{T}$ & G & \\
\hline $\mathrm{T}$ & . & . & . & $T$ & C & . & . & . & . & . & . & $\mathrm{T}$ & & & $\mathrm{T}$ & . & . & $T$ & G & $\mathrm{T}$ \\
\hline $\mathrm{T}$ & . & . & . & $\mathrm{T}$ & C & . & G & . & . & . & . & $\mathrm{T}$ & & A & & . & . & $\mathrm{T}$ & G & . \\
\hline $\mathrm{T}$ & . & . & . & $T$ & C & $T$ & . & . & . & . & . & $\mathrm{T}$ & & & & . & . & $\mathrm{T}$ & G & . \\
\hline $\mathrm{T}$ & & . & & $\mathrm{T}$ & C & $\mathrm{T}$ & & & & & . & $T$ & . & . & . & . & . & $T$ & G & \\
\hline . & . & G & . & $\mathrm{T}$ & C & . & G & . & $\mathrm{T}$ & C & & . & &. & & . & & . & G & \\
\hline . & . & & . & . & C & . & . & . & . & . & . & . & & A & & . & & $\mathrm{T}$ & G & . \\
\hline . & . & & . & & C & . & . & . & . & . & C & . & & . & & . & & . & G & . \\
\hline & . & . & & . & C & & & & & & . & . & . & A & & . & . & . & $\mathrm{G}$ & \\
\hline & & . & $\mathrm{T}$ & & C & & & & & & & & . & & . & & . & & $\mathrm{G}$ & \\
\hline . & . & . & . & . & C & . & . & . & . & . & . & . & & A & & . & . & & G & . \\
\hline . & . & . & . & . & C & . & . & . & . & . & . & . & & & & & . & & G & . \\
\hline . & . & . & . & . & C & . & . & . & . & . & . & . & & A & & & . & & G & . \\
\hline $\mathrm{T}$ & . & & . & $\mathrm{T}$ & C & . & & . & . & . & & $\mathrm{T}$ & & & & & & & & \\
\hline . & . & G & . & $\mathrm{T}$ & C & . & G & . & $\mathrm{T}$ & C & . & $\mathrm{T}$ & & & & & & & & \\
\hline $\mathrm{T}$ & . & . & . & $\mathrm{T}$ & C & . & . & . & . & . & & & & & & & & & & \\
\hline $\mathrm{T}$ & $\mathrm{T}$ & . & & $\mathrm{T}$ & C & & & & & & & & & & & & & & & \\
\hline $\mathrm{T}$ & & . & & $\mathrm{T}$ & C & & & & & & & $\mathrm{T}$ & $G$ & & & & & & & \\
\hline
\end{tabular}

complete mtDNA D-loop sequences that we generated from modern Russian chickens, the five sequences obtained from the archaeological specimens and 32 complete D-loop sequences that represented 11 chicken mtDNA haplogroups reported by Miao et al. (2013) (Table S4).

\section{Results}

\section{Genetic variation of full D-loop region}

We analysed the complete mtDNA control (D-loop) region sequences in 86 chickens from Orloff, Pavlov, Russian White, Yurlov Crower, Uzbek Game and Naked Neck breeds. All the generated sequences from the modern breeds were 1231/1232 bp in length. In total, 35 nucleotide polymorphic sites were observed; transitions were the most common (Table 2). At position $859 \mathrm{bp}$, an insert/deletion (indel) was detected and it was excluded from the phylogenetic reconstructions and MJ network analysis. The 35 variable sites generated 22 haplotypes from the 86 samples with 46 or $53 \%$ of all individuals sharing one dominant haplotype (haplotype E1.1; Table 2 and Table S2). Of the 22 haplotypes, eight were uniquely found in this study: four belonged to the Pavlov breed, and two each to the Orloff and the Yurlov Crower breeds, respectively (Table S2). The Orloff, Uzbek Game and Naked Neck breeds were each defined by four haplotypes while the Pavlov had eleven haplotypes (Table 3). The Yurlov Crower had the highest haplotype diversity $(0.833 \pm 0.098$; Table 3 and Table S3); Pavlov, Orloff, Russian White and the Naked Neck showed almost similar 
Table 3 Nucleotide $(\pi)$ and haplotype (h) diversities of the chicken breeds analysed in this study. $\mathrm{n}$ - number of individuals

\begin{tabular}{|c|c|c|c|c|c|}
\hline Breed & $\mathrm{n}$ & $\begin{array}{l}\text { No. of } \\
\text { haplotypes }\end{array}$ & Haplotypes (frequency) ${ }^{1}$ & $\pi$ & $\mathrm{h}$ \\
\hline Orloff & 12 & 4 & E1.1 (7), E1.8 (1), C1.1 (3), A4 (1) & $0.00418 \pm 0.00107$ & $0.636 \pm 0.128$ \\
\hline Pavlov & 37 & 11 & $\begin{array}{l}\text { E1.1 (22), E1.2 (2), E1.3 (1), E1.4 (2), E1.7 (1), E1.9 (1), E1.10 (1), E1.11 (1), } \\
\text { A1 (1), A2 (1), A3 (4) }\end{array}$ & $0.00307 \pm 0.00073$ & $0.641 \pm 0.088$ \\
\hline $\begin{array}{l}\text { Yurlov } \\
\text { Crower }\end{array}$ & 9 & 5 & E1.1 (1), E1.5 (1), E1.6 (1), E1.12 (3), A7 (1) & $0.00320 \pm 0.00120$ & $0.833 \pm 0.098$ \\
\hline $\begin{array}{l}\text { Russian } \\
\text { White }\end{array}$ & 7 & 3 & E1.1 (2), E1.13 (4), A5 (1) & $0.00279 \pm 0.00162$ & $0.667 \pm 0.160$ \\
\hline $\begin{array}{l}\text { Naked } \\
\text { Neck }\end{array}$ & 9 & 4 & E1.1 (5), E1.9 (1), E1.12 (1), E1.13 (2) & $0.0086 \pm 0.00029$ & $0.694 \pm 0.147$ \\
\hline $\begin{array}{l}\text { Uzbek } \\
\text { Game }\end{array}$ & 12 & 4 & E1.1 (7), E1.12 (2), E1.14 (1), A6 (1) & $0.00198 \pm 0.00108$ & $0.561 \pm 0.154$ \\
\hline
\end{tabular}

${ }^{1}$ Numbers in parenthesis indicate the frequency of haplotype

levels of haplotype diversity (>0.6; Table 3$)$. The Uzbek Game had the lowest level of haplotype diversity at $0.561 \pm 0.154$ (Table 3 ). The nucleotide diversity ranged from 0.00198 (in the Uzbek Game) to 0.0086 (in the Naked Neck) (Table 3). Generally, the Uzbek Game was the least genetically diverse breed as it reported the lowest levels of haplotype and nucleotide diversities.

\section{Phylogenetic relationships and MJ network analysis}

In this study, all the names of the haplogroups follow the designations of Miao et al. (2013) and Liu et al. (2006). The assignment of mtDNA haplotypes generated in this study to the haplogroups observed in global chickens is shown in Table 2. The ML, MP and Bayesian inference trees gave similar topologies lending support to the phylogenetic relationships among existing haplogroups (Figure S1, S2 and S3). The MP tree and the MJ network were therefore chosen for subsequent analysis (Figures 1 and 2).

As expected, the four analyses resolved the phylogenetic relationships of modern domestic chickens as reported in other studies (Liu et al. 2006; Miao et al. 2013; Flink et al. 2014). All the sequences downloaded from the GenBank were separated into distinct clusters corresponding to the haplogroups attributed to them (see Figure 1). Haplogroups I, X and W occupy a basal position in all the three phylogenetic trees and are clearly separated from the other clusters in the MJ network (Figure 2). This corresponds to the results of Miao et al. (2013). The evolutionary proximity between neighbouring and well-resolved clusters that were defined by representative sequences of haplogroups A and B; E1, E2, E3; C1, C2, C3; D;
G, and $F$ (Figure 1) is also in accordance with the findings of Miao et al. (2013). Similarly, the evolutionary position of haplogroup $\mathrm{H}$ remains unclear. On the MP- and ML-tree, it clusters with haplogroups I, W and X (Figure 1, Figure S1 and S2), as defined by Miao et al. (2013), but in the MJ network, as well in the Bayesian tree, it occurs in close proximity to haplogroup D (Figure 2 and Figure S3), a result which corresponds to that of Liu et al. (2006). The uncertain position of haplogroup $\mathrm{H}$, as well as the impossibility of establishing clear genetic relationships between all chicken mtDNA haplogroups based on the analysis of D-loop sequences may be attributed to a low resolving power of this phylogenetic marker and most likely a recent evolutionary divergence of the haplotypes. Despite this, the pattern of evolutionary relationships as seen in Figures 1 and 2 allowed us to assign sequences obtained in this study to three haplogroups A, Cl and El.

Haplogroup $\mathrm{El}$ is the major haplogroup that is observed in the six breeds of Russian chicken. It includes 14 haplotypes representing 73 chicken individuals (Figures 1 and 2; Table 2 and Table S2). This haplogroup consists of a central haplotype, E1.1, with the other 13 haplotypes distributed around it - eight separated by a single mutation step, five by two mutation steps (E1.5, El.6, El.11, E1.12) and one (E1.3) by six mutation steps, respectively from the core haplotype (Figure 2). Ten sequences (comprising of one sequence each from Uzbek Game, Orloff, Russian White and Yurlov Crower, and six from Pavlov) representing seven haplotypes are associated with haplogroup A (Figure 1, Table S2). Haplogroup Cl is defined by a single haplotype that consists of three sequences of the Orloff breed. 


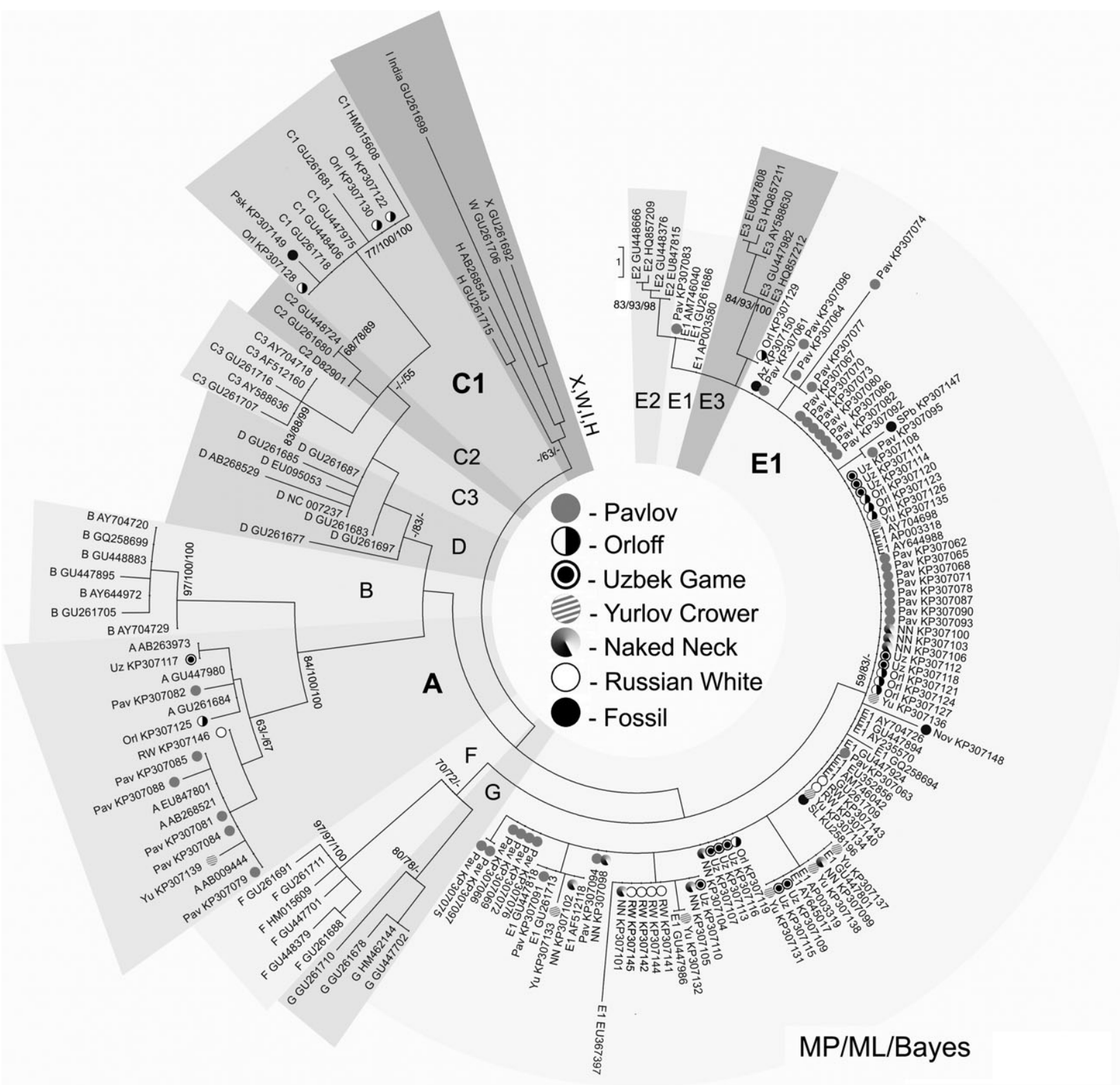

Figure 1 A maximum parsimony/maximum likelihood/Bayesian tree for the 22 haplotypes observed from the analysis of 86 sequences of Russian and Uzbek chicken breeds and 80 references of complete D-loop sequences downloaded from the GenBank (Table S4). Haplogroup definitions are from Miao et al. (2013). Different haplogroups are depicted in different colours. Bootstrap values are presented for the most significant nodes. Abbreviations for chicken breeds used are P - Pavlov, Orl - Orloff, Yu - Yurlov Crower, RW - Russian White, NN - Naked Neck, Uz - Uzbek Game. The fossil specimens from the Novgorod, Staraya Ladoga, Azov, Pskov and Saint Petersburg sites are represented by the abbreviations Nov, SL, Az, Psk, SPb, respectively.

\section{Analysis of archaeological specimens}

To investigate whether the haplotypes found were also present in ancient chickens, we extracted DNA from five fossil chicken bones excavated in the territory of the Russian Plain (Table S3). We successfully amplified a fragment of $167-427 \mathrm{bp}$ in size that spanned the hypervariable region of the mtDNA Dloop from samples recovered from Veliky Novgorod (9th century), Staraya Ladoga (12th century), Azov (13-14th century), Pskov (18th century) and Saint Petersburg (18th century). We identified four haplotypes in these samples and all but one clustered with haplogroup El (Figures 1 and 2). The sequences from 


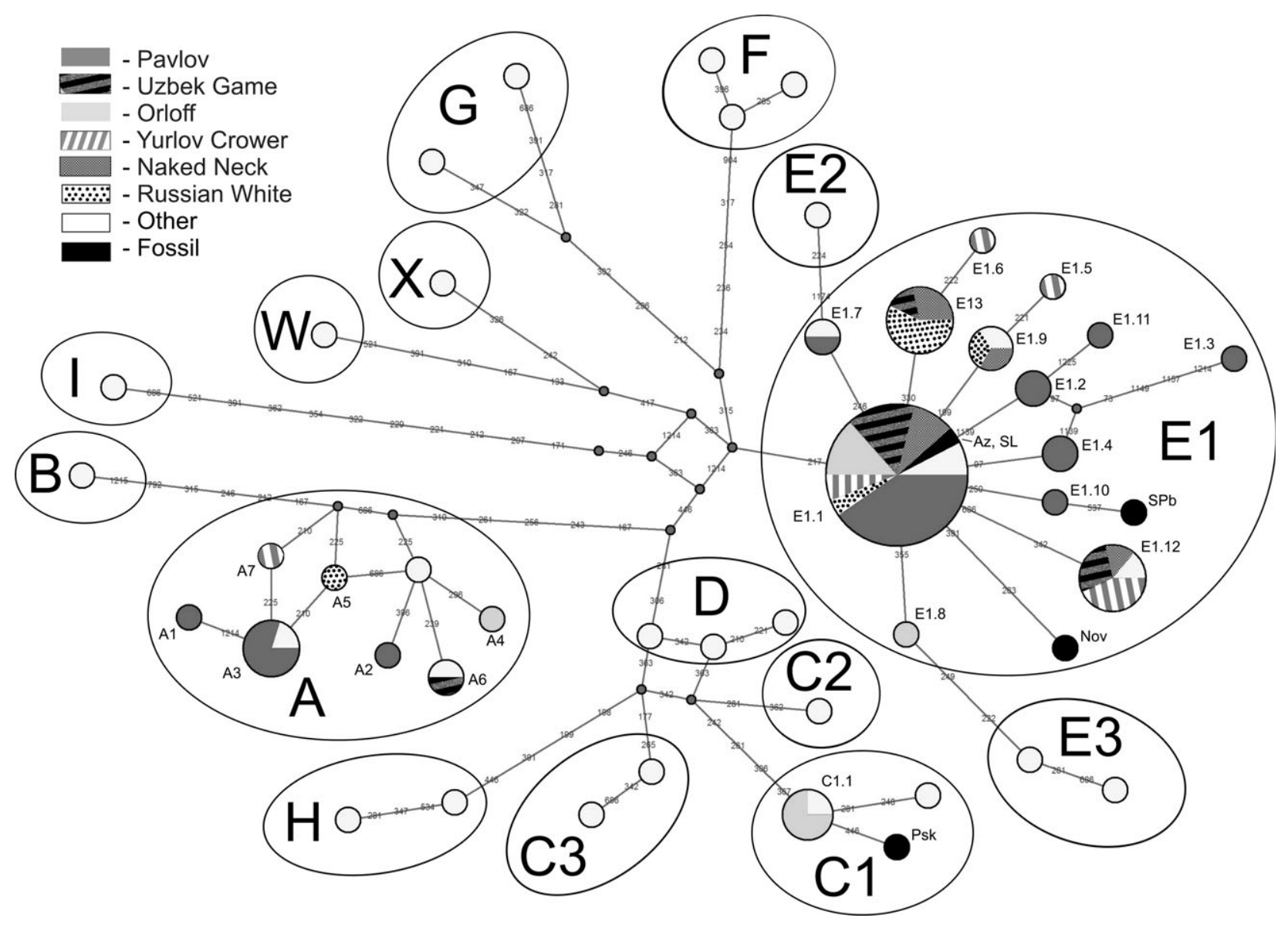

Figure 2 Median-joining network incorporating the 22 haplotypes generated from the analysis of 86 Russian and Uzbek chickens and 32 references of complete D-loop sequences representing 11 haplogroups. Haplogroup definitions are from Miao et al. (2013). Circle sizes are proportional to haplotype frequencies. The number between the haplotype nodes refers to the positions of nucleotide mutations. Different colours in the circle represent various chicken breeds. Black colour represents haplotypes of fossil specimens. Nov, SL, Az, Ps, SPb are abbreviations for fossil specimens from Novgorod, Staraya Ladoga, Azov, Pskov and Saint Petersburg sites, respectively.

Azov and Staraya Ladoga correspond to the core haplotype E1.1, while the haplotypes found in Novgorod and Saint Petersburg were separated from El.1 by one and two mutational steps, respectively (Figure 2). The haplotype from Pskov (KP307149) was associated with the Cl subhaplogroup, and specifically haplotype C1.1 that was observed in the Orloff (Table 2, Figure 1). Interestingly, the three haplotypes associated with the archaeological samples excavated from Novgorod (KP307148), Saint Petersburg (KP307147) and Pskov (KP307149) were not present in any of the modern chickens.

\section{Discussion}

We present here an examination of the mtDNA diversity of Pavlov, Orloff, Yurlov Crower, Russian White, Naked Neck, Uzbek Game chicken breeds that are traditionally raised in the territory of the East European (Russian) Plain. The breeds studied are characterized by different evolutionary histories, some of which are not clear. Despite the diverse backgrounds, all the breeds exhibit haplotypes of the El haplogroup predominating their maternal genetic profiles. This finding corresponds to the results of other studies that have shown that the El haplogroup is the most prevalent among European chickens (Lyimo et al. 2015). All the six breeds share the core El.1 haplotype of the El haplogroup (Figure 2). This haplotype is identical to the one observed in the White Leghorn and White Plymouth Rock breeds of commercial chicken (GenBank accession number AP003317, AP003318). Its concurrent occurrence in Pavlov, Orloff, Yurlov Crower, Russian White, Naked Neck and Uzbek Game originates from a common ancestral population in which the El.1 
haplotype predominates. Liu et al. (2006) suggested that the E haplogroup originated from the Indian subcontinent based on the analysis of $567 \mathrm{bp}$ of the mtDNA D-loop incorporating the hypervariable region. This suggestion was further supported by Miao et al. (2013) who analysed the full mtDNA Dloop and the complete mitochondrial genome.

The E1.1 haplotype seems to be the main haplotype that was present among ancient German, Austrian, British and Greek chickens until the late Middle Ages (Flink et al. 2014). Our samples from Northern Europe (Staraya Ladoga near Lake Ladoga, dated to the 12th century) and from the South of East European Plain (Azov near the Sea of Azov, dated to the 1314th centuries) also belong to haplotype E1.1. It can therefore be deduced that in the past (by no later than the end of the first Millennium AD), the closely related chicken populations harbouring the E1.1 haplotype were common in most of the agriculturally developed territories of Europe, the frontiers of which can now be extended to the northern and eastern borders of the Russian Plain as suggested by our results.

The ubiquitous presence of rare and phylogenetically distant haplotypes can be considered as an indicator of the relatively recent expansion of these genotypes into the East European chicken breed gene pools. Thus, Uzbek Game being a very old breed have the most depleted mitochondrial haplotype diversity in its gene pool, probably due to a small number of unrelated hybridizations, which is in line with the presence of clear morphological breed characteristics and their history. On the contrary, the gene pools of Orloff, Pavlov and Yurlov Crower breeds demonstrate high diversity in mtDNA D-loop haplotypes. These breeds have gone through severe bottlenecks in the first half of the 20th century (Moiseeva 2006) that should have led to the loss of genetic diversity. The high haplotype diversity, observed in this study, may be the consequence of the restoration works on chicken populations that began after the Second World War. As we can see, selection based on breed characteristics and the enhancement of the gene pool through hybridizations with representatives of genetically distant non-European or mixed breeds occurred.

Unlike the other breeds studied here, we detected low contribution of haplotypes from haplogroups other than El to the gene pool of the Russian population of the Naked Neck. This is in line with the observations made for two populations of Transylvanian Naked Neck White and Transylvanian Naked Neck Speckled breeds from Godollo, Hungary (Revay et al. 2010). These populations share two haplotypes E1.1 and E1.9 (Figure S4), which may be due to recent cross-breeding with commercial breeds. Other close haplotypes were unique.

The Naked Neck, Uzbek Game and Russian White are closely related, and they have the largest number of haplotypes in common (E1.1, E1.12, E1.13, Figure 2). A close genetic relationship also exists between Yurlov Crower and Uzbek Game, and they share two common haplotypes (E1.1 and E1.12). Haplotype E1.12 contributes also to the gene pool of the Hinai-dori breed that is related to the famous Shamo fighting chickens (A02 haplotype as referred in Oka et al. 2007). Thus, our study argues for the origin of long-crowing chickens from fighting birds as was suggested by Komiyama et al. (2004).

In addition to the El haplogroup observed, all breeds had haplotypes that defined haplogroup A, with none of the seven haplogroup A haplotypes being shared between breeds. Given that this haplogroup has been suggested to originate from South-East Asia (Liu et al. 2006; Miao et al. 2013), its presence in the territory of the East European Plain seems to suggest an influence of South-East Asia/ Indonesia chicken on the genetic make-up of East European chickens. A similar influence of East Asian chicken was observed in Dutch traditional and western commercial chicken breeds (Dana et al. 2010). The authors observed an erratic occurrence of many different East Asian mitochondrial clades suggesting many independent instances of importation of exotic chickens for enhancing local breeds.

The Cl haplogroup was found only in the Orloff breed. It is worth noting that haplotypes from this haplogroup, originating from South and south-east of China (Miao et al. 2013), are rather rare in European chickens. They have so far been observed in two old Dutch breeds, Booted Bantam and Lakenvelder breeds, that were developed in the 16th and 18th century, respectively (Dana et al. 2010). Taking into consideration that chicken domestication dates to approximately 8000-10 000 years before present (West \& Zhou 1989; Xiang et al. 2014), this time frame is not sufficient for the formation of new D-loop haplotypes (Nabholz et al. 2009). The vast majority of mutations detected in the D-loop of European chicken populations are also found in South and South-East Asia (Miao et al. 2013). Therefore, it is likely that the observed haplotype diversity pre-existed in Asian wild chicken populations prior to domestication. This in turn provides evidence that a long process of chicken domestication in Asia may not have been accompanied by loss of matrilineal genetic diversity.

Sporadic occurrence of a few non-E haplogroup haplotypes in European populations may be the 
results of controlled breeding involving unrelated chicken populations, whose ancestral populations might have a non-European, if counting from the early modern period, origin. We note, that one fossil specimen from Pskov had a sequence that was not associated with the El haplogroup but was assigned to the $\mathrm{Cl}$ haplogroup. This is the first report of the haplogroup occurrence in European chicken populations prior to the 20th century based on the fossil material. Taking into account the estimated age of the Dutch breeds carrying the $\mathrm{Cl}$ haplotype (Booted Bantam and Lakenvelder), fossil Cl specimen may have been brought from Western Europe via Russia, as Pskov was a partner of the Hanseatic League (c. 14001800) and led the active trade with the Western European countries. On the other hand, the 18th century date of the Pskov sample suggests that the Cl haplotype and therefore the $\mathrm{C}$ haplogroup might have been introduced to Europe directly from China, probably from Guangxi and Guangdong provinces, where the C haplotypes are mainly distributed (Liu et al. 2006). At that time, close economic ties and common boundaries were established between the Russian Empire and China.

\section{Conclusions}

Mitochondrial DNA haplogroups A, El and Cl contribute into gene pools of domestic chickens traditionally raised in the territory of the East European (Russian) Plain. This suggests that studied chicken breeds derive their genetic backgrounds from three independent Asiatic source populations. Haplogroup $\mathrm{Cl}$ found in modern and fossil samples represents the genetic signature of chickens originating from the South of China. Our analysis of mtDNA D-loop sequences affirms the early pan-European distribution of the El.1 haplotype (haplogroup E1) chickens and relatively recent introduction of all haplotypes other than El into the East European chicken gene pool.

\section{Acknowledgements}

We are grateful to A.F. Yakovlev and A. Kocinian for assistance in sampling and to N. Grigorieva for fruitful discussion. We would like to acknowledge the assistance from staff of the Research Resource Centers 'Chromas', 'Molecular and Cell Technologies' (Saint Petersburg State University, Saint Petersburg, Russia) and Core Facility 'Geochronology of Cenozoic' (Novosibirsk, Russia). This work was supported by Saint Petersburg State University (Grant Number
1.50.1043.2014) and the Russian Foundation of Basic Research (grant numbers 14 - 04-01469 and 15-2902384 to VT and AD).

\section{References}

Anisimova M., Gascuel O. (2006) Approximate likelihood ratio test for branches: a fast, accurate and powerful alternative. Syst. Biol., 55, 539-552.

Crawford R.D. (1995) Origin, history and distribution of commercial poultry. In: P. Hunton (ed), Poultry Production. Elsevier, Amsterdam, pp. 1-20.

Dana N., Megens H.-J., Crooijmans R.P.M.A., Hanotte O., Mwacharo J., Groenen M.A.M., van Arendonk J.A.M. (2010) East Asian contributions to Dutch traditional and western commercial chickens inferred from mtDNA analysis. Anim. Genet., 42, 125-133.

Druzhkova A.S., Thalmann O., Trifonov V.A., Leonard J.A., Vorobieva N.V., Ovodov N.D., Graphodatsky A.S., Wayne R.K. (2013) Ancient DNA analysis affirms the canid from Altai as a primitive dog. PLOS ONE, 8 , e57754.

Flink L.G., Allen R., Barnett R., Malmström H., Peters J., Eriksson J., Andersson L., Dobney K., Larson G. (2014) Establishing the validity of domestication genes using DNA from ancient chickens. Proc. Natl. Acad. Sci. USA, 111, 6184-6189.

Fumihito A., Miyake T., Sumi S., Takada M., Ohno S., Kondo N. (1994) One subspecies of the red junglefowl (Gallus gallus gallus) suffices as the matriarchic ancestor of all. Proc. Natl. Acad. Sci. USA, 91, 12505-12509.

Fumihito A., Miyake T., Takada M., Shingu R., Endo T., Gojobori T., Ohno S. (1996) Monophyletic origin and unique dispersal patterns of domestic fowls. Proc. Natl. Acad. Sci. USA, 93, 6792-6795.

Hasegawa M., Kishino H., Yano T. (1985) Dating the human-ape split by a molecular clock of mitochondrial DNA. J. Mol. Evol., 22, 160-174.

Hillel J., Groenen M.A., Tixier-Boichard M., Korol A.B., David L., Kirzhner V.M., Burke T., Barre-Dirie A., Crooijmans R.P., Elo K., Feldman M.W., Freidlin P.J., MäkiTanila A., Oortwijn M., Thomson P., Vignal A., Wimmers K., Weigend S. (2003) Biodiversity of 52 chicken populations assessed by microsatellite typing of DNA pools. Genet. Select. Evol., 35, 533-558.

Komiyama T., Ikeo K., Gojobori T. (2004) The evolutionary origin of long-crowing chicken: Its evolutionary relationship with fighting cocks disclosed by the mtDNA sequence analysis. Gene, 333, 91-99.

Liu Y.P., Wu G.S., Yao Y.G., Miao Y.W., Luikart G., Baig M., Beja-Pereira A., Ding Z.L., Palanichamy M.G., Zhang Y.P. (2006) Multiple maternal origins of chickens: out of the Asian jungles. Mol. Phylogenet. Evol., 38, 12-19.

Lyimo C.M., Weigend A., Msoffe P.L., Hocking P.M., Simianer H., Weigend S. (2015) Maternal genealogical 
patterns of chicken breeds sampled in Europe. Anim. Genet., 46, 447-451.

Miao Y.-W., Peng M.-S., Wu G.-S., Ouyang Y.N., Yang Z.Y., Yu N., Liang J.P., Pianchou G., Beja-Pereira A., Mitra B., Palanichamy M.G., Baig M., Chaudhuri T.K., Shen Y.Y., Kong Q.P., Murphy R.W., Yao Y.G., Zhang Y.P. (2013) Chicken domestication: an updated perspective based on mitochondrial genomes. Heredity (Edinb), 110, 277-282.

Moiseeva I.G. (2006) Breed chickens and their gene pools. In: I.A. Zaharov (ed), Genetic Resources of Russian Animal Breeding. Nauka, Moscow, pp. 229-388.

Moiseyeva I.G., Semenova S.K., Bannikova L.V., Filippova N.D. (1994) The genetic structure and origin of an old Russian breed of fowl, the Orlov. Genetika (Moskva), 30, 681-694

Moiseyeva I.G., Romanov M.N., Nikiforov A.A., Sevastyanova A.A., Semyenova S.K. (2003) Evolutionary relationships of Red Jungle Fowl and chicken breeds. Genet. Select. Evol., 35, 403-423.

Mou C., Pitel F., Gourichon D., Vignoles F., Tzika A., Tato P., Yu L., Burt D.W., Bed'hom B., Tixier-Boichard M., Painter K.J., Headon D.J. (2011) Cryptic patterning of avian skin confers a developmental facility for loss of neck feathering. PLoS Biol., 9, e1001028.

Nabholz B., Glemin S., Galtier N. (2009) The erratic mitochondrial clock: variations of mutation rate, not population size, affect mtDNA diversity across birds and mammals. BMC Evol. Biol., 9, 54.

Nei M., Kumar S. (2000) Molecular Evolution and Phylogenetics. Oxford University Press, New York.

Nishibori M., Shimogiri T., Hayashi T., Yasue H. (2005) Molecular evidence for hybridization of species in the genus Gallus except for Gallus varius. Anim. Genet., 36, 367-375.

Niu D., Fu Y., Luo J., Ruan H., Yu X.P., Chen G., Zhang Y.P. (2002) The origin and genetic diversity of Chinese native chicken breeds. Biochem. Genet., 40, 163-174.

Oka T., Ino Y., Nomura K., Kawashima S., Kuwayama T., Hanada H., Amano T., Takada M., Takahata N., Hayashi Y., Akishinonomiya F. (2007) Analysis of mtDNA sequences shows Japanese native chickens have multiple origins. Anim. Genet., 38, 287-293.

Osman S.A., Yonezawa T., Nishibori M. (2016) Origin and genetic diversity of Egyptian native chickens based on complete sequence of mitochondrial DNA D-loop region. Poult. Sci., 95, 1248-1256.

Revay T., Bodzsar N., Mobegi V.E., Hanotte O., Hidas A. (2010) Origin of Hungarian indigenous chicken breeds inferred from mitochondrial DNA D-loop sequences. Anim. Genet., 41, 548-550.
Romanov M.N., Weigend S. (2001) Analysis of genetic relationships between various populations of domestic and jungle fowl using microsatellite markers. Poult. Sci., 80, 1057-1063.

Ronquist F., Huelsenbeck J.P. (2003) MRBAYES 3: Bayesian phylogenetic inference under mixed models. Bioinformatics, 19, 1572-1574.

Sambrook J., Russell D.W. (2001) Molecular Cloning: A Laboratory Manual. Harbor Laboratory Press, Cold Spring.

Siwek M., Wragg D., Sławińska A., Malek M., Hanotte O., Mwacharo J.M. (2013) Insights into the genetic history of Green-legged Partridgelike fowl: mtDNA and genome-wide SNP analysis. Anim. Genet., 44, 522-532.

West B., Zhou B.-X. (1989) Did chickens go north? New evidence for domestication. World's Poult. Sci. J., 45, 205-218.

Xiang H., Gao J., Yu B., Zhou H., Cai D., Zhang Y., Chen X., Wang X., Hofreiter M., Zhao X. (2014) Early Holocene chicken domestication in northern China. Proc. Natl. Acad. Sci. USA, 111, 17564-17569.

\section{Supporting Information}

Additional Supporting Information may be found in the online version of this article:

Figure S1. ML tree of all the D-loop sequences of chickens from this study and 80 reference D-loop sequences downloaded from the GenBank (PDF).

Figure S2. MP tree of all the D-loop sequences of chickens from this study and 80 reference D-loop sequences from the GenBank. All bootstrap values are indicated in (a); bootstrap values $>50 \%$ are indicated at branch nodes in (b) (PDF).

Figure S3. Bayesian tree of all the D-loop sequences of chickens from this study and 80 reference D-loop sequences from the GenBank (PDF).

Figure S4. MP tree of the D-loop sequences of Russian and Hungarian Naked Neck chickens (PDF).

Table S1. List of primers used in this study (PDF).

Table S2. Haplotype names and GenBank accession numbers of chicken mtDNA sequences used for phylogenetic tree and Median-joining network reconstructions (PDF).

Table S3. Description of fossil chicken bones used in this study (PDF).

Table S4. Haplogroup names and GenBank accession numbers of chicken mtDNA sequences used for phylogenetic tree and Median-joining network reconstructions $(\mathrm{PDF})$. 